\title{
Correction to: Germ Cell Tumor Cell Culture Techniques
}

\section{John T. Lafin, James F. Amatruda, and Aditya Bagrodia}

\section{Correction to:}

Chapter 5 in Aditya Bagrodia and James F. Amatruda (eds.), Testicular Germ Cell Tumors: Methods and Protocols, Methods in Molecular Biology, vol. 2195, https://doi.org/10.1007/978-1-0716-0860-9

The chapter was inadvertently published with Acknowledgement section excluded in the article.

This error has now been corrected by including the Acknowledgement section in the chapter. 